\title{
THE EFFECTS OF PERFECTIONISM ON PROACTIVE AND INNOVATIVE BEHAVIORS: ROLE OF PSYCHOLOGICAL CLIMATE
}

\section{DOI: 10.17261/Pressacademia.2020.1263}

PAP- V.11-2020(35)-p.178-184

\section{Pelin Kanten ${ }^{1}$, Yaprak Deniz ${ }^{2}$}

${ }^{1}$ Canakkale Onsekiz Mart University, Faculty of Political Sciences, Canakkale, Turkey. pelinkanten@comu.edu.tr , ORCID: 0000-0002-6487-0203

${ }^{2}$ Canakkale Onsekiz Mart University, Faculty of Political Sciences, Canakkale, Turkey. yaprakdeniz97@icloud.com , ORCID: 0000-0002-2066-1653

To cite this document

Kanten, P., Deniz, Y., (2020). The effects of perfectionism on proactive and innovative behaviors: role of psychological climate. PressAcademia Procedia (PAP), V.11, p.178-184

Permanent link to this document: http://doi.org/10.17261/Pressacademia.2020.1263

Copyright: Published by PressAcademia and limited licensed re-use rights only.

\section{ABSTRACT}

Purpose- This study aims to investigate the effects of perfectionism on proactive and innovative behaviors and the moderating role of psychological climate.

Methodology- For the purpose of the research, the data which were collected from 190 employees who work in a textile industry as a whitecollar worker by the survey method were analyzed by using partial least squares-structural equation modeling method. While conducting analysis, Smart PLS program was used by applying bootstrapping technique (5000 resample) to determine the significance levels of the proposed hypotheses.

Findings- The results revealed that both positive and negative perfectionism have significant effect on proactive behavior levels of employees and also positive perfectionism has a significant effect on innovative behaviors of employees. However, it is found out that psychological climate has a moderating role between positive perfectionism and co-worker oriented proactive behaviors. In addition, it is revealed that psychological climate has a moderating role between positive perfectionism and innovative behaviors.

Conclusion- The study demonstrates that perfectionism is one of the significant personality traits which considered as the determinants of the positive behaviors such as proactive, innovative and other desirable behaviors in organizations. On the other hand, this study reveals that organizational conditions have an importance role on the exhibition of positive behaviors of employees.

Keywords: Perfectionism, proactive behaviors, innovative behaviors, psychological climate.

JEL Codes: M10, M20, M54

\section{INTRODUCTION}

One of the personality characteristics which is called as perfectionism characterized as striving for flawlessness, setting excessively high standards for performance, and employee's disposition to engage in over activity (Harrari et al., 2018: 1121). Perfectionism refers to an "extreme or obsessive striving for perfection, as in one's work" (Dykstra, 2006:1). The term of perfectionism is rooted in people's life because of humans' competitions in workplaces become higher and organizations have a tendency to employ individuals who possess specific personality characteristics (Khodarahimi, 2010: 72). Researchers suggested that perfectionism has positive correlations with indicators of desirable outputs such as positive affect and positive workplace attitudes and behaviors (Besharat and Shahidi, 2010: 428). In literature, researchers suggested that perfectionism has a positive effect on workaholism, work involvement, enjoyment of work and achiev ement of individuals. Moreover, it has been asserted perfectionism has a significant effect on life satisfaction, work engagement and psychological well-being of employees. In this context, it is possible to express that individuals who have a perfectionism can meet positive consequences with their work and social life. Accordingly, it is expected that individuals with higher levels of perfectionism are more tend to engage proactive and innovative behaviors. Therefore, it can be said that also organizational conditions such as climate may have positive effect on these behaviors. Therefore, the purpose of this study is to investigate the effects of perfectionism on proactive and innovative behav iors and determination the role of psychological climate.

\section{THEORETICAL FRAMEWORK AND HYPOTHESES DEVELOPMENT}

Perfectionism represents as a multidimensional personality trait which emphasize achievement orientation and classified as two higherorder dimensions called as perfectionistic strivings and perfectionistic concerns (Olsson et al., 2020: 669). Perfectionistic strivings indicate 
the positive side of this trait that reflect the degree to which people set and strive for the attainment of high performance standards, whereas perfectionistic concerns is considered as the negative aspect of the disposition that shows the degree to which individuals become overly concerned about making mistakes and failing to meet high performance standards (Dunn et al., 2019: 2). Therefore, both positive and negative perfectionism involve to attain high performance requirements in organizations but according to the challenges, individuals reponses may differ. For example, positive perfectionist individuals may have lower level of stress facing the difficulties, while negative perfectionist individuals experience high levels of distress when they could not meet performance standards. In literature, it is seennumerous researches asserted that positiveperfectionism has positive correlations with some desirable outcomes such as positive workplace attitudes and behaviors (Kanten and Yeşiltaş, 2015: 1368). Tziner and Tanami (2013) suggested that positive perfectionism has a significant effect on job engagement and workaholism; Gnilka (2013) stated that positive perfectionism one of the determinants of life satisfaction. Birch et al (2019) indicated that positive perfectionism also has precursors of positive emotions, engagement and well-being. However, Bogdan (2015) emphasized that high standards and perfectionism related to the proactive coping strategies and Musch (2013) focus on that there is a associations between perfectionism and individuals proactive behaviours such as career decision making and career planning. Proactive behaviors characterized as individuals engage in self-starting, future-oriented behavior to change their working conditions and roles (McCormick et al. 2019: 31). These behaviors are defined as'taking initiative in improving current conditions, challenging the status quo rather than passively adapting to present circumstances' (Crant, 2000: 436; Parker et al., 2006: 636). Kanten and Alparslan (2013) classified proactive behaviors in three distinct categories such as organizaitonal, co-worker oriented and individual proactive behaviours and they have suggested that there are individual and organizational antecedents of proactive behaviors. In scope of the individual antecedents of these behaviors for example personality characteristics who are high in learning goal orientation and have high standards may have an impact. Therefore, it is possible to express that employees who has a positive perfectionism, they may more prone to exhibit proactive behaviors, in case who has a negative perfectionism, they may not have a tendency for proactivity, so the following hypotheses are proposed:

$\mathrm{H}_{1}$ : Positive perfectionism influences employees individual proactive behavior levels positively.

$\mathrm{H}_{2}$ : Negative perfectionism influences employees individual proactive behavior levels negatively.

$\mathrm{H}_{3}$ : Positive perfectionism influences employees co-worker oriented proactive behavior levels positively.

$\mathrm{H}_{4}$ : Negative perfectionism influences employees co-worker oriented proactive behavior levels negatively.

$\mathrm{H}_{5}$ : Positive perfectionism influences employees organizational proactive behavior levels positively.

$\mathrm{H}_{6}$ : Negative perfectionism influences employees organizational proactive behavior levels negatively.

Perfectionism is considered as a prevalent disposition in one of the domain of individual's life. In other words, individuals significant part of their life like social life, work life or academic life may be affected from the perfectionism. For example, there are many ways in which perfectionism may have an affect on work life such as high performance and motivation, greater achievement and effectiveness or etc. (Stoeber and Damian, 2016: 265). However, it is suggested that perfectionism has greater impact on creativity motivation and creative thinking style in working area. Accordingly, it is expected that positive perfectionism will enhance creativity by motivating achievementoriented desires and innovativeness (Wigert et al., 2012: 775-776). Nekoie-Moghadam et al. (2012) focus on positive perfectionism is one of the main determinants of creativity and innovative behaviors. Chang et al. (2016) indicate that positive perfectionism positively related to the innovative behaviors. Innovative behavior defined as an complex behaviour consisting of some activities such as "generation of new ideas and the realization or implementation of new ideas". While, idea generation refers to creating novel and useful ideas, idea implementation consist of evaluation of the generated ideas, putting them into practice, and integration of them within the organizational practices. In literature, it is emphasized that there are some individual and organizational antecedents of innovative behaviors. In scope of the individual antecedents personality traits considered as the significant component (Sameer and Ohly, 2017: 5). In this context, it can be inferred that in the individualistic perspective, perfectionism may lead to faciliate employees exhibition of innovative behaviors, so the following hypotheses are proposed:

$\mathrm{H}_{7}$ : Positive perfectionism influences employees exploring opportunity levels positively.

$\mathrm{H}_{8}$ : Negative perfectionism influences employees exploring opportunity levels negatively.

$\mathrm{H}_{9}$ : Positive perfectionism influences employees implementation opportunity levels positively.

$\mathrm{H}_{10}$ : Negative perfectionism influences employees implementation opportunity levels negatively.

Psychological climate refers tothe individual's perception of organizational practices and procedures which havea direct impact on individual performance, satisfaction, and motivation. In other words, it is an overall evaluation of individual's related to the work environment as an adverse or positive (Baltes et al., 2009: 670-671). In literature, it is suggested that psychological climate perceptions are viewed as precursors of some organizational outcomes such as employee attitudes, behaviors, motivation, and performance (Parker et al., 2003: 394) . However, it can be said that psychological climate has a significant effect on organizational commitment, job satisfaction and well-being. Ther efore, it is possible to express that since the employees perceive positive psychological climate, they may have a tendency to behave more positive attitudes towards to their organization. In addition, in case of the individuals possess a perfectionism trait, it is anticipated that they exhibit positive organizational behaviors and the psyhological climate of the organization will be affected from these behaviors, so the following hypothesis are proposed:

$\mathrm{H}_{11:}$ Psychological climate has a moderating effect upon the relationship between positive perfectionism and individual proactive behavior. $\mathrm{H}_{12}$ : Psychological climate has a moderating effect upon the relationship between negative perfectionism and individual proactive behavior. $\mathrm{H}_{13:}$ : Psychological climate has a moderating effect upon the relationship between positive perfectionism and co-worker oriented proactive behavior.

$\mathrm{H}_{14:}$ Psychological climate has a moderating effect upon the relationship between negative perfectionism and co-worker oriented proactive behavior. 
$\mathrm{H}_{15:}$ Psychological climate has a moderating effect upon the relationship between positive perfectionism and organizational proactive behavior.

$\mathrm{H}_{16 \text { : }}$ Psychological climate has a moderating effect upon the relationship between negative perfectionism and organizational proactive behavior.

$\mathrm{H}_{17}$ : Psychological climate has a moderating effect upon the relationship between positive perfectionism and exploring opportunities.

$\mathrm{H}_{18 \text { : }}$ Psychological climate has a moderating effect upon the relationship between negative perfectionism and exploring opportunities.

$\mathrm{H}_{19}$ : Psychological climate has a moderating effect upon the relationship between positive perfectionism and implementation opportunities.

$\mathrm{H}_{20}$ : Psychological climate has a moderating effect upon the relationship between negative perfectionism and implementation opportunities.

Figure 1: Research Model

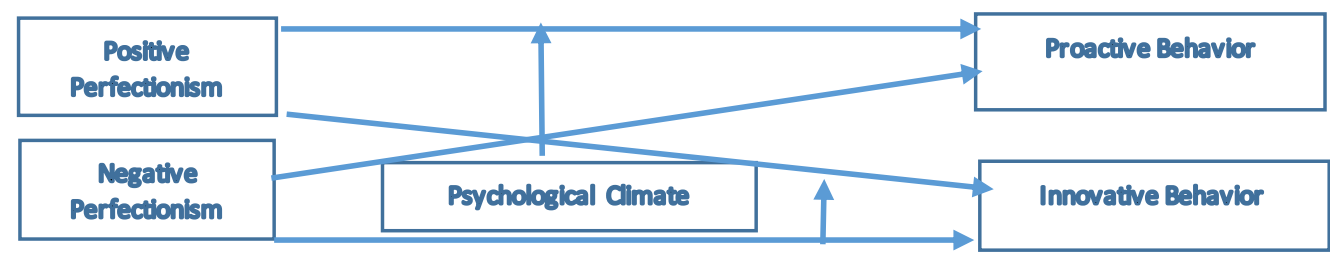

\section{RESEARCH METHODOLOGY}

\subsection{Sample and Procedures}

The present sample of the research was composed of 190 employees who work in textile industry as a white-collar worker which are located in İstanbul province. The participants determined by a convenient sampling method from the different textile enterprises in İstanbul. Out of 280 questionnaires that have been sent out, 220 have been returned, representing a response rate of $78 \%$. After the elimination of the cases that have incomplete data and outliers, 190 questionnaires (67\%) have been accepted as valid and included in the evaluations. However, questionnaire survey method is used for data collection in this study. The questionnaire form contains five different measures related to research variables. Out of the 190 respondents, $63 \%$ were male and $37 \%$ were female; $44 \%$ were between $34-41$ years, $34 \%$ were older than 42 years and $21 \%$ were between 26 and 33 years. In addition, $52 \%$ of the total respondents had a bachelor's degree, $17 \%$ had a high school degree, $17 \%$ of them had a vocational school degree, whereas $14 \%$ had a graduate degree. In addition, majority of participants (76\%) had been working between 1 and 10 years, 24\% of them had been working more than 10 years in the same company.

\subsection{Measures}

The measures used in the questionnaire forms have been adapted from the previous studies in the literature. Perfectionism, innovative and proactive behavior scales were taken from the Turkish literature, psychological climate scale have been adapted to Tur kish and a pilot study has been conducted for the validity of these measures. As a result of the pilot study, some corrections were made in the ques tionnaire forms. A Likert-type metric, that is, expressions with five intervals has been used for answers to the statements of survey. Anchored such; "1strongly disagree, 2- disagree, 3- agree or not agree, 4- agree, 5-strongly agree". Moreover, 5 demographic questions were included in the questionnaire form. Firstly, all scales were subjected to the exploratory factor analyses to check the dimensions, and then confirmatory factor analyses were applied to all scales.

Perfectionism Scale: Perfectionism scale was taken from Kanten and Yeşiltaş (2015) study. Exploratory factor analyses using principle component analysis with varimax rotation was applied to the adapted scale to check the dimensions. As a result of the perfectionism scale variables, 9 items were removed from the analysis due to the factor loading under 0.50 and two factor solutions (positive perfectionism and negative perfectionism) were obtained in accordance with the theoretical structure.

Innovative Behavior Scale: Employees' innovative behavior levels were measured with 19 items which was taken from Yeşiltaş et al. (2013) studies. As a result of the exploratory factor analyses, 11 items were removed from the analysis due to the factor loading under 0.50 and two factor solution (exploring and implementation opportunities) were obtained in accordance with the theoretical structure.

Proactive Behavior Scale: Employees proactive behavior levels were measured with 18 items of "Proactive Behavior Scale: A Study of Validity and Reliability" which was developed by Kanten and Alparslan (2013). As a result of the exploratory factor analyses, 5 items were removed from the analysis due to the factor loading under 0.50 and three factor solution (organizational proactive behaviors, co-worker oriented proactive behaviors and individual proactive behaviors) were obtained in accordance with the theoretical structure.

Psychological Climate Scale: Employees psychological climate perception levels were measured with 17 itesm which were taken from Brown and Leigh (1996) study. As a result of the exploratory factor analysis of the data related to the psychological climate variables, 8 items were removed from the analysis due to the factor loading under 0.50 and one factor solution obtained in accordance with the theoretical structure.

\subsection{Data Analysis}

SPSS for Windows 22 and SmartPLS v3 were used to analyze the obtained data. SPSS 22 version used for the descriptive statistics and reliability analysis and assessing the demographic profile of the sample. Smart PLS v3 used for testing the hypotheses by employing partial least squares-structural equation modeling method. Therefore, partial least squares (PLS) based SEM was used in this study. PLS is consider ed as a well known method for estimating path coefficients in structural models and also it is seen prominent in management literature in the 
last decade due to its capable under the non-normality conditions and small samples (Ali and Kim, 2015: 302). While conducting analysis, Smart PLS program was used by applying bootstrapping technique ( 5000 resample) to determine the significance levels of the proposed hypotheses.

\section{RESEARCH FINDINGS}

\subsection{Measurement Model}

In scope of the measurement model, convergent validity and discriminant validity were tested. Within the convergent validity, factor loadings, composite reliability (CR), and average variance extracted values were computed. Table 1 shows that factor loadings exceeded the recommended value of 0.6 and composite reliability values greater than the recommended value of 0.7 and also average variance extracted is exceeded the recommended value of 0.5 (Hair et al., 2006).

Table 1: Summary Table of Validity and Reliability

\begin{tabular}{|l|c|c|c|c|}
\hline Variables & Factor Loadings & Cronbach's Alpha & Composite Reliability & Average Variance Extracted (AVE) \\
\hline $\begin{array}{l}\text { Co-Worker Oriented Proactive } \\
\text { Behaviors }\end{array}$ & $0.731-0.773$ & 0.613 & 0.795 & 0.564 \\
\hline Exploring Opportunities & $0.744-0.835$ & 0.781 & 0.859 & 0.603 \\
\hline Individual Proactive Behaviors & $0.739-0.829$ & 0.666 & 0.881 & 0.599 \\
\hline $\begin{array}{l}\text { Organizational Proactive } \\
\text { Behaviors }\end{array}$ & $0.696-0.925$ & 0.797 & 0.810 & 0.714 \\
\hline Positive Perfectionism & $0.549-0.873$ & 0.642 & 0.892 & 0.596 \\
\hline Psychological Climate & $0.791-0.902$ & 0.820 & 0.791 & 0.735 \\
\hline Implementation Opportunities & $0.729-0.774$ & 0.606 & 0.821 & 0.559 \\
\hline Negative Perfectionism & $0.673-0.837$ & 0.744 & & 0.536 \\
\hline
\end{tabular}

The next step as part of the measurement model was to assess the discriminant validity. Discriminant validity provided when the square root of the AVE (diagonal values) of each construct is larger than its corresponding correlation coefficients (Fornell \& Larcker, 1981). Table 2 shows that each indicator's loadings on its own construct are higher than all cross loadings with other constructs. Thus, it can be said that measurement model showed convergent validity and discriminant validity criteria were provided.

Table 2: Discriminant Validity

\begin{tabular}{|c|c|c|c|c|c|c|c|c|}
\hline Variables & $\begin{array}{l}\text { Co-Worker } \\
\text { Oriented } \\
\text { Proactive } \\
\text { Behaviors }\end{array}$ & $\begin{array}{l}\text { Exploring } \\
\text { Opp. }\end{array}$ & $\begin{array}{l}\text { Ind. Proact. } \\
\text { Beh. }\end{array}$ & $\begin{array}{l}\text { Org. } \\
\text { Proactive } \\
\text { Behaviors }\end{array}$ & $\begin{array}{l}\text { Positive } \\
\text { Perfect. }\end{array}$ & $\begin{array}{l}\text { Psych. } \\
\text { Climate }\end{array}$ & Imp. & $\begin{array}{l}\text { Negative } \\
\text { Perfect. }\end{array}$ \\
\hline Exploring Opp. & 0.454 & 0.777 & & & & & & \\
\hline Ind. Proactive Beh. & 0.298 & 0.597 & 0.774 & & & & & \\
\hline Positive Perfect. & 0.336 & 0.470 & 0.461 & 0.328 & 0.772 & & & \\
\hline Psych. Climate & 0.302 & 0.348 & 0.255 & 0.185 & 0.152 & 0.857 & & \\
\hline Impl. & 0.353 & 0.347 & 0.129 & 0.189 & 0.175 & 0.522 & 0.747 & \\
\hline Negative Perfect. & -0.072 & -0.249 & -0.282 & -0.330 & -0.175 & 0.021 & -0.012 & 0.732 \\
\hline
\end{tabular}

\subsection{Structural Model}

With using Smart PLS v3 and bootstrapping procedure by 5000 iterations structural model and hypotheses were tested. In this step, for the explanation power the standardized $\mathrm{R}^{2}$ and for assessing the model fit standardised root mean square residual (SRMR) were computed. In this model SRMR value was observed 0.079 which is under the recommended value of 0.08 , shows that model has an acceptable. $R^{2}$ is an important variable for the evaluation of models' exploratory powers. PLS-SEM path model aims at maximizing the $R^{2}$ of endogenous latent variable. In studies, $0.25,0.50,0.75$ values are assessed respectively as small, moderate and large (Hair et al., 2014). According to this, (positive and negative perfectionism) and psychological climate (modearator variable) explain $30 \%$ of the employees organizational proactive behaviors; $59 \%$ of the individual proactive behaviors and also explain $40 \%$ of the co-worker oriented proactive behaviors. In addition, positive perfectionism and psychological climate (modearator variable) explain 57\% of the exploring opportunities and also explain 58\% of the implementation of opportunities which are considered as the significant components of innovative behaviors. 
Figure 2: Structural Model

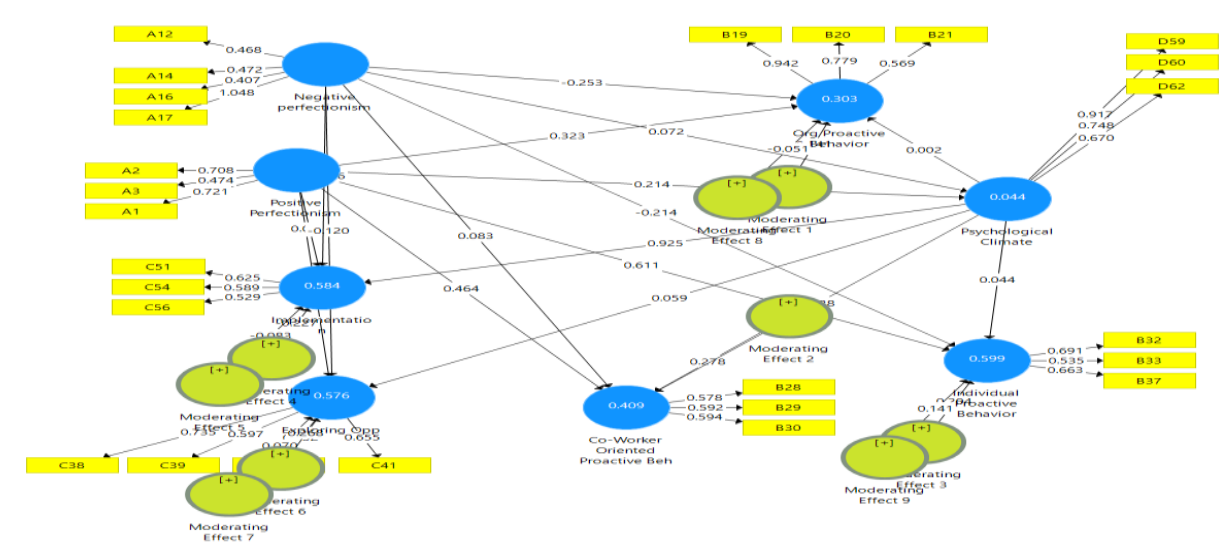

According to the structural model, it is possible to express that the path parameter and significance levels show that positive perfectionism has a positive and significant effect on individual proactive behavior levels of employees $(\beta=0.405$; $t$-value $=5.571)$ and also negative perfectionism has a negative and significant effect on individual proactive behavior levels of employees $\left(\beta=-0.209\right.$; $t$-value $=2.661$ ); so $\mathrm{H}_{1}$ and $\mathrm{H}_{2}$ hypotheses were supported. However, positive perfectionism has a positive and significant effect on co-worker oriented proactive behavior levels of employees $(\beta=0.294$; $t$-value $=4.062)$ and also positive perfectionism has a positive and significant effect on $(\beta=0.248 ; t-$ value=3.998) organizational proactive behaviors of employees, thus $\mathrm{H}_{3}$ and $\mathrm{H}_{5}$ hypotheses were supported. On the other hand, negative perfectionism has a negative and significant effect on organizational proactive behavior levels of employees $(\beta=-0.257 ; t-v a l u e=2.570)$ and $\mathrm{H}_{6}$ hypothesis was supported. In addition, positive perfectionism has a positive and significant effect on innovative behavior dimension which is called as exploring opportunites; $\left(\beta=0.401\right.$; $\mathrm{t}$-value $=5.543$ ), $\mathrm{so}_{7}$ hypothesis was supported. In this study, it is tested the moderating role of psychological climate upon the effect of positive and negative perfectionism on proactive behaviors. The moderating effect of psychological climate is positive and significant $(\beta=0.142$; $t$-value $=2.028)$ on the relationship between positive perfectionism and co-worker oriented proactive behaviors so $\mathrm{H}_{13}$ hypothesis was supported. Moreover, the moderating effect of psychological climate is positive and significant $\left(\beta=0.166\right.$; $\mathrm{t}$-value $=2.159$ ) on the relationship between positive perfectionism and exploring opportunites so $\mathrm{H}_{17}$ hypothesis was supported.

\section{CONCLUSION}

Perfectionism is regarded as an important personality disposition as to provide contribution employees to exhibit positive attitudes and behaviours in an organizational life. In literature, it is suggested that positive perfectionism lead to increasing some favourable outcomes such as work engagement, psychological well-being and life satisfaction and also result in decreasing of stress and emotional exhaustion levels. However, it is expected that employees who have possess a positive perfectionism trait, they may exhibit positive behaviors such as organizational citizenship behaviors, innovative and proactive behaviors. On the other hand, from the organizational conditions, it should be ensured that positive working conditions required for attaining desirable consequences. In other words, besides employees personality traits, it is needed to maintain humane organizational policies and procedures to provide employees behave in an positive manner. Accordingly, it can be said that the psychological climate which is perceived by the employees considered as an crucial component for the employee's positive attitudes and behaviors towards to their organizations. Therefore, these positive behaviors depended on both employe es personality traits and the organizational conditions. In scope of this study, both one of the significant personality trait called as perfectionism and psychological climate from the organizational perspective were taken as an antecedents of the proactive and innovative behaviors.

As a result of the research findings, it has been revealed that employees' proactive behaviors which are classified as individual, organizational and co-workers oriented are affected positively or negatively depending on the perfectionism type. For example, while positiv e perfectionism has a positive and significant effect on individual proactive behaviors, negative perfectionism has a negative and significant effect on this behavior. Therefore, it can be said that white collar employees who have a positive perfectionism trait, they may have tendency to explore career opportunities and take part in career-related activities. However, research results indicate that positive perfectionism both have a positive and significant effect on co-worker oriented and organizational proactive behaviors. Accordingly, it can be infferred that due to the white collar employees have high performance standards and striveness for achievement, they have willingness to self-starting, future and change oriented behaviors and also have prone to exhibit helping behaviors towards their colleagues. On the other hand, employees who have negative perfectionism trait not to have tendency to make an effort for their organizations due to the fear of failure or concern of making mistake. Besides, positive perfectionism has a positive and significant effect on one of the dimension of innovative behaviors called as exploring opportunities. That is to say, white collar employees based on their perfectionism may incline to explore opportunities for creating a change in an organizational context. Moreover, it is found out psychological climate has a moderator role upon the effect of positive perfectionism on co-worker oriented proactive behaviors. According to this result, it can be inferred that by the positive perfectionism has an important precursors of proactive behaviors, it is needed white collar employees to perceive positive working conditions in an organizational context. In addition, research results demonstrate that psychological climate has a moderator role upon the effect of 
positive perfectionism on exploring opportunities. Thus, it can be said that incase of the employees positive perfectionism trait, they wish to perceive qualified working condition as to behave in a creative manner.

Consequently, it is possible to express that proactive and innovative behaviors depended on both individual traits and organizational conditions. In the literature, there are many studies which examined proactive and innovative behaviors antecedents, but there is no study investigating positive and negative perfectionism, psychological climate, proactive and innovative behaviors together in the textile industry. However, based on the research results, it can be supposed to hire and employ individuals who have positive perfectionism trait which lead to increase favourable outcomes in an organizational context. In addition, it can be recommended to the establishments to mainta in positive working conditions which can be facilitate employees to behave in a positive manner. For future studies, the research model can be tested on larger samples in other industries. Besides, the study can be expanded by adding other variables which are classified as important consequences of perfectionism such as job embeddedness, workholism or withdrawal intentions etc. Moreover, from the organizational perspective pay fairness or pay satisfaction may be taken as a mediator or moderator variable which can be affective on white collar employees attitudes and behaviors.

\section{REFERENCES}

Ali, F. \& Kim, W.G. (2012). Creative Tourists' Experience: Does it Predict Satisfaction, Nostalgia Intensity and Behavioural Intentions. International Interdisciplinary Business-Economics Advancement Conference, Conference Proceedings, November 16-21, 2015, Ft. Lauderdale, Florida, USA, ISSN: $2372-5885,296-307$.

Baltes, B.B., Zhdanova, L.S. \& Parker, C. P. (2009). Psychological climate: A comparison of organizational and individual le vel referents. Human Relations, 62(5), 669-700.

Besharat, M.A. \& Shahidi, S. (2010). Perfectionism, anger, and anger rumination. International Journal of Psychology, 45 (6), $427-434$.

Birch, H. A., Riby, L. M., \& McGann, D., (2019). Perfectionism and PERMA: The benefits of otheroriented perfectionism. Intern ational Journal of Wellbeing, 9(1), 20-42. doi:10.5502/ijw.v9i1.749.

Bogdan, C. (2015). Learning experience, proactive coping, high standards and undergraduate students' initial orientation toward the graduate studies programs in psychology. Procedia - Social and Behavioral Sciences, 187, $647-652$.

Brown, S.P. \& Leigh, T. (1996). New Look at Psychological Cimate and Its Relationship to Job Involvement, Effort and Perform ance. Journal of Applied Psychology, 81(4), 358-368.

Chang, H., Chou, Y., Liou, J. \& Tu, Y. (2016). The effects of perfectionism on innovative behavior and job burnout:Team workplace friendship as a moderator. Personality and Individual Differences, 96, 260-265.

Crant, J.M. (2000). Proactive Behavior in Organizations. Journal of Management, 26 (3), 435-462.

Dunn, J.G.H., Gotwals, J.K., Dunna, J.C. \& Lizmore, M.R. (2019). Perfectionism, pre-competitive worry, and optimism in high-performance

youth athletes. International Journal of Sport and Exercise Psychology, 1-16.

Dykstra, E.E. (2006). Relationship of Perfectionism and Gender to Academic Performance and Social Functioning in Adolescents. Doctor of Philosophy, Indiana University.

Gnilka, P.B., Ashby, J.S., \& Noble, C.M. (2013). Adaptive and Maladaptive Perfectionism as Mediators of Adult Attachment Styles and Depression, Hopelessness, and Life Satisfaction. Journal of Counseling \& Development, 91, 78-86.

Hair, J. F., Hult, G. T. M., Ringle, C. M., \& Sarstedt, M. (2014). A primer on partial least squares structural equations modeling (PLS-SEM). London: Sage Publications.

Harari, D., Swider, B.N., Steed, LB. \& Breidenthal, A. P. (2018). Is Perfect Good? A Meta-Analysis of Perfectionism in the Workplace. Journal of Applied Psychology, $103(10), 1121-1144$

Kanten P. \& Yeşiltaş M. (2015). The Effects of Positive and Negative Perfectionism on Work Engagement, Psychological Well-being and Emotional Exhaustion. Procedia Economics and Finance, 1367-1375.

Kanten P. \& Alparslan A.M. (2013). Proactive Behavior Scale: A Study of Validity and Reliability. Selçuk Üniversitesi Sosyal Bilimler Meslek Yüksekokulu Dergisi, $16,21-43$.

Khodarahimi, S. (2010). Perfectionism and five-big model of personality in an Iranian sample. International Journal of Psychology and Counselling, 2(4), 72 -79.

McCormick, B.W., Guay, R.P., Colbert, A.E. \& Stewart, G.L. (2019). Proactive personality and proactive behaviour: Perspectives on person-situation interactions. Journal of Occupational and Organizational Psychology, 92, 30-51

Musch, E. (2013). The Impact of Perfectionism Type on the Career Self-Efficacy, Vocational Identity, and Interest Differentiation of College Students. Doctor of Philosophy, The Florida State University College of Education, Florida.

Nekoie-Moghadam, M., Beheshtifar, M. \& Mazrae-Sefidi, F. (2012). Relationship between employees' perfectionism and their creativity. African Journal of Business Management, 6(12), 4659-4665.

Olsson, L.F., Hill, A.P., Madigana, D.J. \& Woodley, G. (2020). Development of perfectionism in junior athletes: Exam ination of actual and perceived parental perfectionism. Journal of Sports Sciences, 38(6), 669-675.

Parker, S.K., Williams, H.M. \& Turner, N. (2006). Modeling the Antecedents of Proactive Behavior at Work. Journal of Applied Psychology, 91 (3), $636-652$.

Parker, C.P., Baltes, B.B., Young, S.A., Huff, J.W., Altmann, R.A., Lacost H.A. \& Roberts, J.E. (2003). Relationships between psychological 
climate perceptions and work outcomes: a meta-analytic review. Journal of Organizational Behavior, 24, 389-416.

Sameer, Y.M. \& Ohly, S. (2017). Innovative Behavior of Employees: A model of Antecedents and Consequences, ADeeper Look at Psyc hological and Organizational Factors. Working Paper No. 45, Faculty of Management, German University in Cairo.

Stoeber, J. \& Damian, L.E. (2016). Perfectionism in Employees: Work engagement, workaholism, and burnout. In F.M. Sirois \& D.S. Molnar (Eds). Perfectionism health, and well-being. Springer, New York.

Tziner, A., \& Tanami, M. (2013). Examining the links between attachment, perfectionism, and job motivation potential with job engagement and workaholism. Journal of Work and Organizational Psychology, 29, 65-74.

Wigert, B., Reiter-Palmon, R., Kaufman, J.C. \& Silvia, P.J. (2012). Perfectionism: The good, the bad, and the creative. Journal of Research in Personality, 46, 775779.

Yeşiltaş M., Kanten P., Kanten S., Hüseyin Ç. \& Zorlu Ö. (2013). Öğrenme Odaklılığın ve İşin Özelliklerinin Yenilikçi Davranışlar Üzerindeki Etkisi. 14.Ulusal Turizm Kongresi, KAYSERI, TÜRKIYE, 5-8 Aralık 2013, 121-143. 